\title{
The effects of electric shock isolation in serial learning
}

DAVIO C. RASKIN, MAUREEN HATTLE AND EDWIN W. RUBEL MICHIGAN STATE UNIVERSITY

Mild electric shock was used to isolate the seventh syllable in a 12-item serial list of nonsense syllables. The shock isolation produced the usual von Restorff effect. In addition, the isolation produced a spread of effect to adjacent items and facilitated the learning of the entire list. The results were interpreted in terms of enhanced orienting reflexes produced by the shock.

In a recent review of the von Restoreff phenomenon, Wallace (1965) concluded that isolating one item in a serial list facilitates the learning of that item, but such facilitation occurs at the expense of the other items in the list. The findings with respect to the spread of effect to adjacent items in the list have been inconsistent. Some studies (Jones \& Jones, 1942; Smith, 1948; Smith \& Stearns, 1949; McLaughlin, 1966) have shown varying amounts of facilitation of learning either or both of the adjacent items, whereas other studies have either failed to find such effects (Jensen, 1962; Roberts, 1962; Smith, 1949) or have found decreased learning of an adjacent item (Jenkins \& Postman, 1948). Of the numerous studies, only two (McLaughlin, 1966; Smith \& Stearns, 1949) have given any indication that isolation results in more rapid learning of the entire list.

All of the previous studies have produced isolation by innocuous procedures such as printing an item in a different color or inserting a different type of item within an otherwise homogeneous list. The present experiment was designed to determine if isolation by a more significant stimulus such as mild shock would produce a spread of the isolation effect to other items in the list and facllitate overall learning.

\section{Method}

Forty-five volunteers from introductory psychology served as Ss. They learned a 12-item serial list of nonsense syllables by the anticipation method, pronouncing each syllable before it appeared. The list was composed of CVC trigrams of $42 \%$ association value from the Krueger (1934) norms, and it was presented at a 2-sec rate on an MTA Scholar teaching machine. The 6-sec intertrial interval (ITI) consisted of two 2-sec blanks followed by a 2-sec presentation of asterisks.

The Shock Isolation Group (SI) received a brief electric shock which coincided with the appearance of the seventh item on each trial. In order to control for any general effects produced by electric shock, the Control Shock Group (CS) received a shock on each trial at the beginning of the second blank of the ITI. A second Control Group (C) received no shock during learning. There were $15 \mathrm{Ss}$ in each group. The shock was produced by the discharge of a 100 mfd capacitor charged to $67 \mathrm{~V}$. It was triggered automatically by the teaching machine and was delivered to the $S$ through silver electrodes attached to the index and third fingers of the right hand.

All Ss were familiarized with the shock by the presentation of three shocks prior to beginning the learning task. They were then told that they might receive occasional shocks while they were learning the list, and learning was continued to a criterion of two successive perfect trials. $S$ was terminated if he did not reach the criterion within 40 trials.

\section{Results}

Speed of learning of each item was measured by the trial on which the last error on that item occurred. The mean trial of last error for each serial position is shown in Fig. 1. In order to test the isolation effect produced by the shock, an analysis of variance was performed on the scores for Item 7 in the three conditions. There was a significant difference in mean trial of last error $(F=8.79, d f=2 / 42, p<.001)$. A Duncan Multiple Range Test indicated that the SI group learned Item 7 significantly sooner $(p<.001)$ than the other two groups, which did not differ from

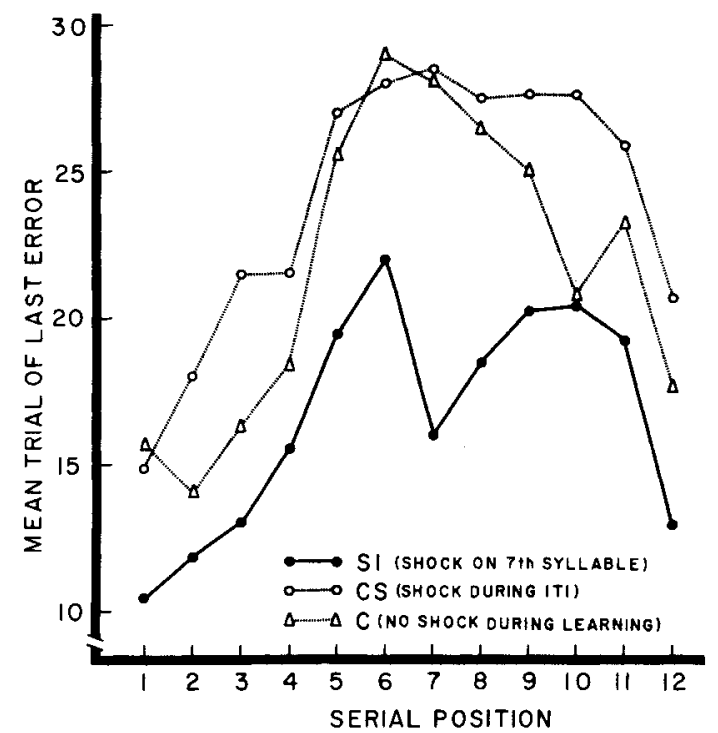

Fig. 1. Mean trial of last error at each serial position for the three groups. 
each other. The spread of effect of shock isolation to adjacent items was also tested by Duncan tests. The SI group learned Item 8 significantly sooner $(p<.05)$ than the two control groups. The SI group also learned Item 6 sooner than the CS group $(p<.05)$ and sooner than the $\mathrm{C}$ group $(\mathrm{p}<.10)$.

Since eight Ss failed to reach the criterion within 40 trials, the speed of learning the entire list was evaluated by the trial on which the last error occurred. The mean trial of last error was 23.5 for the SI group, 30.4 for the CS group, and 30.3 for the C group. Analysis of variance indicated that the difference between groups was significant $(F=3.47$, df $=$ $2 / 42, p<.05$ ), and the Duncan test showed that the SI group learned the list significantly faster than the other two groups.

\section{Discussion}

The procedure of pairing electric shock with an item in the middle of a serial list of nonsense syllables produced a very strong effect as shown by the earlier learning of that item by the SI group. In addition, there was a spread of the isolation effect which resulted in faster learning of the items adjoining the shocked item. Contrary to the findings of almost all of the studies which have used other isolation procedures, the use of electric shock as an isolator resulted in facilitation of learning the entire serial list.

The overall facilitating effect of electric shock isolation cannot be attributed to generalized effects of electric shock stimulation such as increased drive. On each trial, the CS group received the same amount of shock as the SI group, but the performance of the CS group was as poor as the $C$ group, which received no shock during learning. It may be inferred from these results that the facilitating effect of electric shock during serial learning occurs only when the shock is paired with the appearance of an item in the list. Under such conditions, particular items in the list may become signals for the occurrence of the shock, producing increased attention to those items. According to an orienting reflex (OR) interpretation of attention (Maltzman \& Raskin, 1965; Sokolov, 1963) stimuli are given signal value by pairing them with a significant stimulus such as electric shock, and the OR to such signal stimuli is maintained at a higher level. The occurrence of large ORs to the middle items of the list should result in faster learning of those items, and thereby facilitate the learnIng of the whole list. Since the shock in the CS condition occurred during the ITI which was highly discriminable without the addition of an external stimulus, it may be assumed that the first blank period of the ITI very quickly became a signal for the occurrence of the shock. Under those conditions, items of the list would have relatively little signal value. Therefore, the items of the list would not produce larger ORs, and facllitation of learning would not be expected in the CS group.

The above explanation implies that concurrent measures of physiological indicators of the OR, such as the galvanic skin response, would show that changes in the rate of learning of the items under different isolation conditions would be accompanied by corresponding changes in the magnitude of the OR evoked by the items. Previous research by other investigators (Brown, 1937; Kintsch, 1965; Thompson \& Obrist, 1964) has demonstrated that the rate of learning of items in verbal tasks is related to the occurrence of ORs to those items, and research is in progress to directly test the above interpretation of the von Restorff phenomenon.

\section{References}

Brown, C. H. The relation of magnitude of galvanic skin responses and resistance levels to the rate of learning. $J$, exp. Psychol., 1937, 20, 262-278.

Jenkins, W. O., \& Postman, L. Isolation and spread of effect in serial learning. Amer. J. Psychol., 1948, 61, 214-221.

Jensen, A. R. The von Restorff isolation effect with minimal response learning. J. exp. Psychol., 1962, 64, 123-125.

Jones, F. N., \& Jones, Margaret H. Vividness as a factor in learnlists of nonsense syllables. Amer. J. Psychol., 1942, 55, 96-101.

Kintsch, W. Habituation of the GSR component of the orienting reflex during paired-associate learning before and after learning has taken place. J. Math. Psychol., 1965, 2, 330-341.

Krueger, W. C. F. The relative difficulty of nonsense syllables. J. exp. Psychol., 1934, 17, 145-153.

Maltzman, I., \& Raskin, D. .C. The effects of individual differences in the orienting reflex on conditioning and complex processes. J. exp. res. Person., 1965, 1, 1-16.

McLaughlin, J. P. The von Restorff effect in serial learning: serial position of the isolate and length of list. J. exp. Psychol., 1966, $72,603-609$.

Roberts, W. A. A further test of the effect of isolation in serial learning. Amer. J. Psychol., 1962, 75, 134-139.

Smith, M. H., Jr. Spread of the isolation effect in serial learning. Amer. Psychol., 1948, 3, 235 (Abstract).

Smith, M. H., Jr. The influence of isolation on immediate memory. Amer. J. Psychol., 1949, 62, 405-411.

Smith, M. H., Jr., \& Steams, Ellen G. The influence of isolation on the learning of surrounding materials. Amer. J. Psychol., $1949,62,369-381$.

Sokolov, E. N. Perception and the conditioned reflex. New York: Macmillan, 1963.

Thompson, L. W., \& Obrist, W. D. EEG correlates of verbal learning and overlearning. EEG clin. Neurophysiol., 1964, 16, 332342 .

Wallace, W. P. Review of the historical, empirical, and theoretical status of the von Restorff phenomenon. Psychol. Bull., 1965, $63,410-424$. 